A R R TII C C U L O O D E I NVESTIGACIÓN C I E E N T T I F I C A $A$

TEC N O L Ó G I C A

\title{
LA NUEVA NOVELA HISTÓRICA FICCIÓN-REALIDAD DEL HÉROE
}

\author{
THE NEW HISTORIC FICTION-REALITY NOVEL \\ OF THE HERO
}

Por: Carolina López Sánchez*

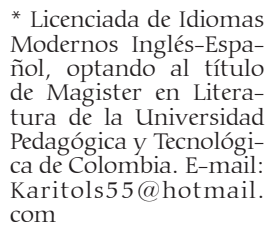

Recibido: 1 de febrero de 2017 - Aprobado: 16 de junio de 2017

\section{RESUMEN}

La nueva novela histórica toma la realidad histórica con sus aconteceres para convertirlos en el asunto central de la novela. El objetivo del presente trabajo parte de la pregunta icómo a través de la ficción se presenta a un personaje de la historia (Simón Bolívar) como un héroe real y desvanecer el concepto del héroe intachable?, creando una reflexión sobre las situaciones que se presentan en la realidad a la cual se pertenece; para el desarrollo del trabajo se toman bases teóricas desde: Nueva novela histórica, ficción-realidad, héroe y la obra la carroza de Bolívar del escritor colombiano Evelio Rosero Diago. La novela instiga a descubrir la otra faceta de Bolívar y desvanecer la concepción tradicional de héroe. La propuesta permite tomar desde la posición de la literatura la inclinación por lecturas de Nueva novela histórica, donde los personajes históricos (héroes) se muestran como hombres de carne y hueso, para ver que también tuvieron sentimientos con aciertos y desaciertos, con equivocaciones como la humanidad de nuestra cotidianidad, y ponernos a la par como hombres que somos, capaces de reconocernos y a la vez de reconocer al otro, así la Nueva Novela Histórica permite dar mayor significación a la narrativa.

Palabras clave: nueva novela histórica, ficción-realidad, héroe.

\begin{abstract}
The new historical novel takes the historical reality with its events to turn them into the central subject of the novel. The objective of the present work starts from the question ihow a personage of the history (Simón Bolívar) is presented, through the fiction, like a real hero and dispel the concept of the impeccable hero?, creating a reflection on the situations that are presented in the reality to which one belongs; in order to develop this work theoretical bases are taken from: New historical novel, fiction-reality, hero and Bolivar's carriage of the Colombian writer Evelio Rosero Diago. The novel instigates to discover the other side of Bolivar and fade the traditional conception of hero. The proposal allows to take from the position of the literature the inclination for readings of New historical novel, where the historical personages (heroes) are shown like men of flesh and bone, to see that they also had feelings with successes and mistakes, with mistakes like humanity of our daily life, and put ourselves at the same time as men that we are capable of recognizing ourselves and recognizing the other, so the New Historical Novel allows greater significance to the narrative.
\end{abstract}

Keywords: new historical novel, fiction- reality, hero. 


\section{Introducción}

l presente artículo presenta un avance del proyecto de investigación para optar el título de magíster en literatura, en el cual se propone analizar al héroe en la novela La carroza de Bolívar, del escritor colombiano Evelio Rosero Diago. La novela está enmarcada en la nueva novela histórica; se convierte en una mezcla de realidad-ficción sobre un acontecer o un héroe histórico, y así ofrecer al lector la intriga, la duda, y la construcción de una nueva reflexión que conlleve a un pensamiento crítico constructivo.

Algunas de estas novelas se centran en dar explicación y sentido a la realidad de una época, donde se desarrollan unos hechos históricos, ahora en la carroza de Bolívar los hechos pasan a segundo plano, para dar paso a centrar la atención en la vida y su acontecer en los hombres, que sin importar su condición en la sociedad siguen siendo humanos y no seres de piedra.

Es por medio de la literatura en la cual se encuentra el goce, la distracción y el conocimiento, y en esta ocasión el acercamiento a la historia, como en el caso de la novela en estudio La carroza de Bolívar, es una historia que se atreve a lo irreverente al mostrar la parte negativa del héroe Simón Bolívar, con el fin de insistir en un cambio frente a la percepción facilista de construir héroes o líderes erróneos, el desarrollo del trabajo se apoya en las teorías de: nueva novela histórica, ficción, realidad y héroe. El objetivo general consiste en: analizar la carnavalización del héroe, en La Carroza de Bolívar, como manifestación ficcional de la nueva novela histórica.

La carroza de Bolívar es una obra publicada en 2012, se enmarca en la nueva novela histórica, la cual tiene sus orígenes en Latinoamérica en 1949. Evelio Rosero en su obra evidencia su investigación en fuentes históricas para tomar referencias sobre la vida de Simón Bolívar y así presentar una trama que se entreteje entre la verdad y la farsa, entre la apariencia y la burla para carnavalizar al héroe Simón Bolívar. La carroza de Bolívar es un texto literario que establece relaciones intertextuales, vinculando el discurso histórico para justificar con sólidos argumentos la ficcionalización que se le hace a la imagen de Simón Bolívar, quizás con el fin de involucrar al lector y despertarle la intriga, la sospecha, respecto a la idea que se tiene de este gran prócer, como generalmente se le denomina el gran libertador, padre de la patria, entre otras.

En esta investigación se desarrolla en torno a la pregunta ¿Cómo analizar la ficción narrativa que caracteriza la novela La carroza de Bolívar?, la cual 
muestra la carnavalización del héroe y 'demoniza' la figura de Bolívar, acudiendo a fuentes no oficiales que desacralizan la historia oficial. En esta dirección, se destaca que la obra de Evelio Rosero comparte con la de otros artistas la irreverencia que se atreve a romper cánones impuestos desde la autoridad de la representación histórica, que se nos impone desde pequeños como la única verdad posible que, a golpes de autoridad, en la práctica impide tener otras versiones e indagar las otras posibilidades del discurso histórico.

La investigación es de carácter interpretativa sobre la lectura de la obra La carroza de Bolívar de Evelio Rosero Diago, tomando como referencia para su interpretación la teoría hermenéutica de Gadamer. La interpretación estará basada, desde un análisis a la obra con relación a la carnavalización del héroe, para este desarrollo se tomará como punto de inicio la obra, se seguirá el avance de esta interpretación con el estudio de la novela histórica, para luego contextualizar al autor y su trayectoria en este género, y por último avanzar hacia la función narrativa y la ficción en la obra, resaltando lo que se propone frente a la concepción de héroe.

\section{Género literario}

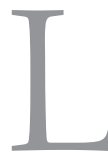

os escritores se inspiran en diferentes motivos, razones, ideales e intereses los cuales se manifiestan en sus creaciones; es así como sus historias se identifican por una temática, formando parte de un género específico que pude ser: lírico, narrativo o dramático, por ejemplo, Todorov define el género literario: "como "una agrupación de textos con propiedades comunes". Y a su vez, cada género se divide en subgéneros literarios, por lo cual del género narrativo se encuentra la novela, que consiste en narrar una secuencia de hechos para formar así una historia, desarrollada por unos personajes que se comunican por un diálogo y por lo general un narrador presenta dicha historia. De esta mima forma la novela presenta también una clasificación, de acuerdo al tema y a unas características donde estará la nueva novela histórica.

\section{Nueva novela histórica}

a literatura ofrece posibilidades de reconocer y comprender el mundo y
su contenido y ahora muestra la relación con la historia; en donde la
narración juega con la realidad y la ficción, pues la literatura rescata
un pasado, lo recupera, lo enfrenta y lo revive, no lo deja morir en el olvido
y esto es lo que ofrece la nueva novela histórica. Es así como Evelio Rosero
en su obra toma a un personaje histórico que es tomado desde la realidad 
como lo fue Simón Bolívar y lo convierte en el tema del personaje central de la obra que es Justo Pastor, donde se emplean los diferentes recursos literarios y así crear su novela La carroza de Bolívar para revivir el pasado de un reconocido hombre de la historia colombiana y a la vez presentarnos detalles de su vida, pues esa es la intención de una novela desde la teoría, en donde se considera es:

Imagen de la vida es la novela, y el arte de componerla escrita en reproducir los caracteres humanos, las pasiones, las debilidades, lo grande y lo pequeño, las almas y las fisonomías, todo lo espiritual y lo físico que nos constituye y nos rodea, y el lenguaje que es la marca de raza, y las vivencias, que son el signo de familia, y la vestidura, que diseña los últimos trazos externos de la personalidad: todo esto sin olvidar que debe existir perfecto fiel de balanza entre la exactitud y la belleza de la reproducción. (Amoros, 1989, pág. 36).

En este sentido la nueva novela histórica permite la reinterpretación del pasado de nuestra historia colombiana tomando las voces del pueblo pastuso que vivió una amarga experiencia con el gran prócer Simón Bolívar, que para muchos es desconocida y que a pesar del pasar de los años se continúa viviendo en una sociedad donde la autoridad continua cometiendo atropellos; Gabriel Garcia Marquez en García Dussán (2006), expresa que:

Para volver sobre un pasado que no cesa de pasar la cuenta de cobro por la exclusión y la falta de conciliación nacional, se trata de la evidencia del fracaso de los proyectos liberales de fundación: somos conscientes de nuestros males, pero nos hemos desgastado luchando contra los síntomas mientras las causas se eternizan, nos han escrito y oficializado una versión complaciente de la historia hecha más para esconder que para clarificar, en la cual se perpetúan vicios originales, se ganan batallas que nunca se dieron y se socializan glorias que nunca merecimos, pues nos complacemos en el ensueño de que la historia no se parezca a la Colombia en que vivimos. https://dialnet. unirioja.es/servlet/articulo?codigo $=1431144$

Evelio Rosero no asume a Bolívar desde la percepción de la historia oficial, sino que presenta una serie de datos que han sido omitidos por la historia siendo este el asunto que le inquieta al personaje. 
La novela es lo nuevo, "novela se deriva de novela las cosas nuevas las nuevas historias". (Amorós, 1989, p. 11). De esta forma la novela se presenta con novedades dadas por un autor, en relación a la variedad de temáticas, apareciendo así diferentes categorías como, por ejemplo: novela clásica, novela romántica, novela realista, novela del costumbrismo, novela psicológica, etc. A principios del siglo XX, la novela inicia un movimiento centrípeto hacia el interior de América en busca del ser profundo, y a partir de los años cuarenta propone un cambio, deja ver una realidad más compleja, "la novela no sirve más a la realidad, sino que se sirve de la realidad "(Ainsa, 2003, pág. 25).

La novela se interesa en la búsqueda de un nuevo lenguaje narrativo que permita mostrar los distintos factores históricos, y las grandes corrientes literarias se convierten en un proceso de continuidad de historias. Así se da cabida a la nueva novela, es decir a "aquella que se incorpora a la trayectoria novelística, renovándose técnicamente. Esta novela viene a llenar el vacío que había llevado a los creadores y críticos a pensar en el agotamiento o la agonía de la novela como género literario". (Ainsa, 2003, pág. 17). Existen unas características propias de la novela como lo son: "La novela intenta reflejar con más exactitud la auténtica realidad: cada personaje se define por sus palabras y sus obras mucho más que por la caracterización previa que de él nos hace". (Ainsa, 2003, pág. 80).

Entre la historia y la literatura existe un nexo inseparable, porque en las dos, se reúne el devenir de la humanidad; la literatura como arte brinda un reflejo recreado de la realidad histórica, capaz de tocar las fibras más sensibles del intelecto humano. Mientras que la historia se interesa más por dar a conocer unos datos o hechos y no se centra en estudiar la condición humana, como si lo hace la narrativa, que se centra en re- humanizar y construir al hombre en su condición de hombre y no de héroe siendo esta otra de las características de la nueva narrativa "buscar sin solemnidad al individuo, a hombres y a mujeres en su dimensión más auténtica". (Ainsa, 2003, pág. 101). Pero es en la novela histórica, donde se toma un suceso o un personaje histórico y se va más allá de lo que los documentos netamente históricos revelan, en esta forma el autor pone en juego toda su imaginación recreándola en la obra como lo deja ver Rosero.

La novela histórica es la que logra captar toda la atención del lector: "una novela histórica necesita un argumento que se mantenga por sí mismo y capte la atención del lector más allá de las formas de vida, las costumbres, 
las creencias y los prejuicios de un momento histórico determinado" (Martin, 2003, pág. 15).

En esta forma La carroza de Bolívar logra con su relato mantener la atención del lector, quien está sujeto a la expectativa sobre la carroza que desfilará en el festival de blancos y negros celebrado en Pasto. La carroza de Bolívar es una obra dividida en tres partes: en la primera parte relata la historia del Doctor Justo Pastor Proceso López, un famoso ginecólogo de Pasto, lugar donde será desarrollada la trama, el Doctor es el protagonista principal que nos deja ver su monótona vida y el interés por escribir sobre Simón Bolívar, pero según él con la verdadera verdad, apoyado con testimonios reales y de apuntes del historiador José Rafael Sañudo:

El doctor Proceso se había propuesto una obra que describiera con claridad meridiana no solamente las actuaciones políticas y militares del mal llamado Libertador, sino las otras, de orden humano, que acabarían de esclarecer el monumental error histórico que se constituía conceder a Bolívar un noble protagonismo en la independencia de los pueblos, protagonismo que sí tuvo, desde luego, consideraba el doctor, pero el más nefasto. (Rosero, 2012, pág. 61).

La segunda parte, es el asunto que marca la pauta en la novela donde se justifica que pertenece a la Nueva Novela Histórica: en donde se toma hechos que son tomados de una realidad histórica, ya que "la historia no se ocupa de posibilidades sino de realidades de lo que ocurrió realmente, la historia se ocupa de hechos, de hechos reales, antes que de sucesos imaginados" (White, 1992, p.372). y Evelio Rosero deja muestra de sus investigaciones: "Bolívar quería ser posible todos los éxitos para sí. Eso no lo digo yo, lo vuelve a comprobar Sañudo en sus Estudios: nos dice que el 23 de agosto de 1821 Bolívar escribió a Santander que pensaba ir a libertar a Quito". (Rosero, 2012, pág. 173).

Así es el asunto con Simón Bolívar, que para Justo Pastor fue solo un embaucador, en esta parte se muestra como a través de una noche de tertulia a puertas cerradas en casa del doctor hablan sobre las injusticias que hizo Simón Bolívar. Él se habia convertido en obsesión para el Justo Pastor y que había encontrado la forma de hacerlo público a través de una carroza, aprovechando el carnaval de blancos y negros, para lo cual es advertido por sus amigos de que es mejor no hacerlo: "mejor quedémonos tranquilos con esto del mal llamado Libertador, Justo Pastor, lo van a perjudicar igual que 
a mí, abandone usted su libro, ya Sañudo lo hizo mejor; viva su vida, coma callado, o lo desguevan" (Rosero, 2012, p. 194); y la tercera parte es la trama que se da alrededor del grupo de exestudiantes universitarios, quienes se están organizando como un grupo de guerrilla que según ellos son los justicieros y defenderán a como dé lugar el buen nombre del Libertador.

La carroza de Bolívar rescata una verdad silenciada y reconstruye una realidad histórica que cuestiona la falta de criterio en las decisiones tanto personales como colectivas, que de una u otra forma afectan el presente en el que se presenta cada uno.

\section{Realidad}

T a carroza de Bolívar está ubicada en una época real, como lo fue la década de los sesenta, donde se estaban dando cambios políticos para Colombia; a su vez la lectura invita a detenerse quizás para ir a las fuentes, para conocer y descubrir un poco más sobre el asunto del Libertador Simón Bolívar que la novela presenta; de esta forma la lectura no pasa desadvertida, sino que hace eco en la realidad que circunda a la humanidad, porque el personaje histórico Simón Bolívar que se toma en la obra se encuentra en las diferentes plazas donde muchos se detienen y observan la estatua del prócer, ya sea por simple curiosidad, por conocimiento o porque les llama la atención para tomar una buena fotografía, es un Simón Bolívar que siempre aparece sin importar si es una gran ciudad o un pequeño pueblo.

La obra ofrece una lectura donde se da una relación entre historia y ficción, siendo la historia un referente de realidad, la cual ha sido trastocada por la ficción a través de unos personajes que son construidos con unas vidas de ficción concedidas por el autor. Donde Justo Pastor es el personaje central, quien toma a un personaje real como lo fue Simón Bolívar para bajarlo de la concepción de héroe, y así ofrecer al lector una nueva lectura de la historia oficial. En la nueva novela histórica se presentan dos categorías que son la realidad y la ficción; pero es desde la realidad de donde se toma el eje central en la novela histórica entendiendo que:

La novela aspira a reflejar la realidad lo más perfectamente, es evidente que dependerá, ante todo, del concepto que se tenga de la vida. Por eso las teorías filosóficas no solo se dan en algunas novelas, sino que dan lugar a nuevos tipos de novelas. No hace falta ser muy 
idealista para sostener que la vida del hombre concreto es una serie de factores muy diversos: ambientales, económicos, sociológicos, históricos, psicológicos, ideológicos, afectivos... una novela que pretenda ser completa, darnos una visión total de la vida de unos personajes tendrá que atender, en mayor o menor grado, a todos ellos. La novela es también un arte, que el novelista es el creador de una realidad artística (Amoros, 1989, pág. 172).

Realidad que se refleja en la obra, porque en la historia: "los elementos del campo histórico se organizan en una crónica mediante la ordenación de los hechos que se deben tratar en el orden temporal en que ocurrieron" (White, 1.992 , p.6). Entonces se encuentra en la novela unos hechos que fueron desarrollados en tiempos reales "Bolívar, que pertenecía a la nobleza criolla de Venezuela, visitó Europa, asistiendo en 1804 a la coronación de Napoleón como emperador y a su investidura de la corona de Hierro en Lombardía en 1805". (Rosero, 2012, p.151).

Son fechas que si se verifican, coinciden con los datos que la historia oficial ofrece; o porque no, hablar también del contexto en el que se desenvuelve la obra como lo son los carnavales de blancos y negros que aun hoy se siguen desarrollando del 4 al 6 de enero con grandes carrozas que desfilan por las principales calles de Pasto, de esta forma se basa el autor en datos reales que construyen la narración en una trama que logra reunir algunos de los personajes que representan la sociedad pastusa en la sala de la casa del doctor Justo Pastor para socializar sobre los aspectos negativos que marcaron la vida de Bolívar, justificando la desentronización de gran héroe. "la problematicidad de los vínculos entre historia y literatura surge a partir del deslinde entre la concepción tradicional de la historia, entendida como "relato de sucesos memorables" ocurridos en el pasado cercano o remoto, y la fundación moderna, en el transcurso de los siglos XVII y XIX". (Seydel, 2007, p.13).

\section{¿Qué es la ficción en la narrativa?}

n la narrativa se define: ficción como transposición a contextos que es preciso imaginar. En cualquier discurso puede haber ficciones: cada vez que se suscita en un contexto imaginario, es decir, no presente, no real, que es necesario reconstruir, y siempre y cuando ambos interlocutores convengan en tomar lo imaginario por imaginario, estamos ante un discurso ficticio. (Reyes, 1984, pág. 27). 
La ficción de la narración va haciendo partícipe al lector, atrapándolo, gracias a la magia de enlazar una secuencia con relación a lo que se cuenta, contrario a lo que hace la historia que es imitar un suceso o un hecho. Pero la ficción necesita de lo real para reproducirse y algunos autores se valen de espacios históricos, hechos e incluso de referencias concretas como los son sus personajes, donde se ficciona la construcción del existir, al alterar la realidad vivida, de esa forma se permite construir desde la trama real, una trama imaginaria. Pues "la historia refleja los efectos y no las causas, lejos de esa metáfora del tiempo que es hombre, víctima de la historia alimentados por la ficción". (Ainsa, 2003, pág. 97).

La obra nos presenta una familia y a unos personajes de la ficción que se reúnen en torno a un tema que es real (Simón Bolívar) y la historia es desarrollada en un evento real como lo es el carnaval de blancos y negros en Pasto. Sin embargo, a pesar de tomarse un personaje real de la historia oficial, no se queda en relatar lo que esta dice; sino que se presenta una serie de datos que han sido omitidos por la historia siendo este el asunto que le inquieta al personaje central quien también a su vez lleva una vida de falsas apariencias, pero que llega un momento de la vida en que decide un cambio y siente la necesidad de la verdad; quizá sea la razón por la cual tome como pretexto a un hombre de renombre como lo es Simón Bolívar calificándolo como hombre de frialdad y dominio, quien no se detuvo a contemplar las consecuencias de sus actos, solo tenía un fin que se debía lograr a costa de lo que fuera. Para mostrarse ahora el doctor Justo con su verdadera faceta sin importar los criterios de los demás, porque se ha cansado de la monotonía de una vida de fracaso y falsedad.

La carroza de Bolívar es una obra de ficción, ya que el autor quien también se convierte en historiador como lo dice White: "El historiador está liberado del tener que decir algo acerca del pasado; el pasado no es más que una ocasión para la invención de melodías ingeniosas" (White, 1.992, p. 355). Así la narración del relato, muestra como la magia de enlazar unos acontecimientos reales en unos personajes imaginarios, van despertando la curiosidad del lector quien se pregunta ¿Cómo así?, ¿por qué? y ¿qué razones hay para mostrar otra cara de Bolívar?

El autor juega con el intelecto del lector, para hacerlo una ficha más del juego de la creación, para que el lector crea, corrobore, constate la verdad o siga construyendo el imaginario. "Por medio de la imaginación 
pueden ponerse en duda las imágenes históricas fijas y provocar que se desmoronen" (Seydel, 2007, p.100) y Rosero no solo se quedó en revelar hechos históricos, sino que los mezcló con la imaginación y se centró en la figura de Bolívar para convertirlo en el tema central de la obra. "Escribir sobre Simón Bolívar no es nuevo y muchos autores lo han hecho, quizás este héroe de la historia con su ímpetu revolucionario, su pasión desbordada fama criolla, ha entusiasmado a los escritores de finales del siglo XX e inicios del XXI." (Montoya, p.28).

\section{Héroe}
T a literatura y la historia ofrecen una gran variedad de héroes en donde la imaginación del escritor y la del lector continúan construyéndolo, adicionándole nuevos poderes acordes con la evolución de la tecnología o mágicos como los héroes de la épica; y cada cultura genera sus héroes capaces de suplir las falencias que el ser humano presenta.

Entre las definiciones de héroe se toma la que consigna el "Diccionario de la Lengua Española de la Real Academia (Madrid, 1970, p 703), bajo esta voz; entre los antiguos paganos el que creían nacido de un dios o diosa y de una persona humana por la cual le reputaban más que un hombre y menos que un dios, como Hércules, Aquiles, Eneas, Etc. 2. Varón ilustre y famoso por sus hazañas o virtudes // 3. El que lleva a cabo una acción heroica // 4. Personaje principal. (Bauza, H. 2007, p. 10).

Desde estas definiciones se ubica a Simón Bolívar en la numero dos (varón ilustre y famoso por sus hazañas o virtudes), pero es esta definición de héroe la que en la novela se pone en duda, y mucho más cuando la figura de respeto (Simón Bolívar) se quiere carnavalizar en forma exagerada en el carnaval, donde el pueblo se alborota y sale en algarabía, de jolgorio en el ambiente festivo todas las clases sociales se reúnen, se mezclan en las calles el carnaval envuelve con su ambiente de desorden, es un caos, pero con el pretexto de fiesta es el momento donde el espíritu dionisiaco revive y allí nada importa y menos en detenerse a ver que es verdad o mentira; simplemente hay que ir por donde la gente va; evidenciando así que nuestra raza no es un pueblo de reflexión ni de cambios, porque nos da miedo y los antecedentes de la historia nos deja ver que somos un pueblo sometido y sumiso y aun hoy seguimos dando la continuidad a esa falencia a pesar de avanzar en algunos aspectos, quiéralo o no el pasado se repite. 
La verdad se manifiesta y se da a la luz pública mostrando la parte oscura de los supuestos líderes de aquellos que llevan en sus propuestas el futuro de nuestro porvenir, pero que no repercuten en nuestras decisiones porque al final no participamos en los cambios, permanecemos en el silencio, y actuamos como si nada pasara frente a las diferentes problemáticas que hoy vivimos y que, aunque nos afecten actuamos como si nada pasara.

\section{Conclusiones}

velio Rosero en la narración literaria de su obra, La carroza de Bolívar, 1 entrecruza la historia, que es una realidad del pasado histórico con la narración literaria que corresponderá a la ficcionalización de la creación. Un juego entre la historia y la novela, donde el lector hará su propia interpretación.

La lectura de "La carroza de Bolívar", aporta al intelecto el conocimiento en una forma didáctica, a través de los efectos de la ficción que influyen en el relato histórico para cuestionarnos ¿Cómo consigue el autor todas estas fuentes biográficas?, quizás trabajo de años y cuantos más para recrearlas. Son historias realmente sorprendentes, tan llenas de ¿verdades o de mentiras? Al igual que la complicada relación entre la ficción y la realidad. Acaso lo real está en la ficción, desde ese "ayer" que recrea a héroes de grandes ideas, pero no como seres perfectos, sino como seres humanizados. O iestá primero la ficción sobre la realidad? Una obra que sorprende.

La obra la carroza de Bolívar, pertenece a la nueva novela histórica que no solo ofrece una narración, una expresión, un hecho de una época o a un personaje, sino que además es una reflexión que refleja la crisis de nuestro país, Colombia. Donde estas circunstancias que tienen sus orígenes desde la historia, el sistema social refleja que quienes están al poder sin importar la época continúan la misma formación en la ley del silencio y el comodín, de seguir manipulados por unos y sometidos por otros, con miedo a la verdad y acostumbrados al silencio y en esta forma construyendo la injusticia en una sociedad llamada Colombia.

\section{REFERENCIAS BIBLIOGRÁFICAS}

Ainsa, F. (2003). Narrativa hispanoamericana del siglo XX. España: Prensas Universitarias de Zaragoza.

Amorós, A. (1989). Introducción a la novela contemporánea. Madrid: Cátedra. 
Bauza, H. (2007). El mito del héroe. Morfología y semántica de la figura heroica. Argentina: Fondo de Cultura Económica de Argentina S.A.

Diccionario de la Lengua Española de la Real Academia. Madrid, 1970, p 70.

García Dussán, Pablo (2006). La narrativa colombiana del posboom: Una enmienda de la literatura decimonónica. Pontificia Universidad Javeriana Colombia. Disponible en: https://dialnet. unirioja.es/servlet/articulo?codigo $=1431144$

Gutiérrez, J. F. (1935). Bolívar y su obra. Imprenta del departamento de Bucaramanga.

Menton, S. (1993). La nueva novela histórica de América Latina, 1979-1992. México. D.F.: Fondo de Cultura Económica.

Montoya, P. (2009). Novela histórica en Colombia 1998- 2008. Entre la pompa y el fracaso. Medellín: Universidad de Antioquia.

Negret, R. (1921). La campaña del sur y especialmente la Batalla de Bombona. Imprenta del Estado Mayor General.

Reyes, G. (1984). Polifonía textual la citación en el relato literario. España: Gredos. S.A.

Rosero, E. (2012). La carroza de Bolívar. México: Tusquest.

Silva, M. (2010). Ficción e historia: Estudios de la literatura colombiana. 36-152.

Seydel, U. (2007). Narrar historias la ficcionalización de temas históricos por las escritoras mexicanas Elena Garro, Rosa Beltrán y Carmen Boullosa (un acercamiento transdisciplinario a la ficción histórica. Iberoamericana): Verveut.

\section{Infografía}

http://ntc-narrativa.blogspot.com/2012_01_02_archive.html

http://www.revistacredencial.com/credencial/content/en-entrevista-evelio-rosero

https://dialnet.unirioja.es/servlet/articulo?codigo $=1431144$ 